\title{
Course of lung function in children with cystic fibrosis in their first 3 years of life
}

\author{
Juan E. Balinotti, M.D..$^{a, b}$, Daniel V. Chang, M.D. ${ }^{a}$, Silvina Lubovich, M.D. ${ }^{a}$, \\ Viviana Rodríguez, M.D. ${ }^{a}$, Silvina Zaragoza, M.D. ${ }^{a}$, Natalia Escobar, M.D. ${ }^{a}$, \\ Carlos Kofman, M.D. ${ }^{a}$, Gabriela L. Pérez, M.D. ${ }^{c}$, Victoria Ardiles, M.D. ${ }^{c}$ \\ and Alejandro Teper, M.D. ${ }^{a}$
}

\begin{abstract}
Introduction. The early prevention of respiratory complications in children with cystic fibrosis is determining for a longer survival. The implementation of lung function tests in the first months of life allows to detect respiratory involvement, even in asymptomatic children. Objective. To assess the course of lung function in children with cystic fibrosis in their first 3 years of life and identify the factors affecting it.

Population and methods. Observational, retrospective, analytical study. Children younger than 36 months with at least 2 lung function tests were included.

Results. Between 2008 and 2016, 48 patients were included; $85 \%$ of them had been diagnosed by newborn screening. The first lung function test was done at 5 months old. The median Z-score of maximal flow at functional residual capacity was -0.05 (interquartile range: -1.09 to 1.08). The median change in the maximal flow Z-score between tests was -0.32 (interquartile range: -1.11 to 0.25$), p=0.045$. Patients with Staphylococcus aureus respiratory infections, especially methicillin-resistant SA, evidenced a greater deterioration of lung function compared to those without infection. Neither sex nor the type of genetic mutation were associated with the course of lung function. Nutritional recovery throughout the study was really good. Conclusion. Lung function in children with cystic fibrosis worsens progressively during their first 3 years of life. These findings are associated with Staphylococcus aureus respiratory infections.

Key words: cystic fibrosis, lung function tests, newborn screening.
\end{abstract}

http: / / dx.doi.org/10.5546/aap.2019.eng.323

This study was conducted with the support of a Biomedical Science Research Fellowship "Florencio Fiorini" for year 2018, granted by the Fundación Florencio Fiorini and the Argentine Association of Medicine.

Conflict of interest: None.

Received: 6-11-2018.

Accepted: 4-4-2019 To cite: Balinotti JE, Chang DV, Lubovich S, Rodríguez V, et al. Course of lung function in children with cystic fibrosis in their first 3 years of life. Arch Argent Pediatr 2019;117(5):323-329.

\section{INTRODUCTION}

Cystic fibrosis (CF) is the most common autosomal, recessive genetic disorder in Caucasian individuals. ${ }^{1}$ In Argentina, its incidence is 1 per 7213 live births. ${ }^{2}$ In relation to morbidity and mortality, $90 \%$ of cases are the result of progressive lung disease. ${ }^{3}$ In low-resource countries, survival does not exceed 15 years, whereas in first-world countries, it extended from 15 years in 1954 to 41 years in $2015 .{ }^{1}$ This was mainly thanks to the early detection of respiratory complications and a more energetic clinical and therapeutic approach since a much early age. ${ }^{4,5}$

In 2002, the Autonomous City of Buenos Aires implemented a newborn screening program for the detection of CF. This allowed to diagnose CF at a much earlier age. Many of these children did not present symptoms at the time of diagnosis. Several studies done in young children with CF using lung function tests, ${ }^{6,7}$ chest computed tomography, ${ }^{8-10}$ and inflammatory marker levels in bronchoalveolar lavage material ${ }^{11,12}$ demonstrated airway involvement in the first months of life.

Lung function tests are done in children younger than 3 years only in a few centers worldwide, and are not yet part of routine clinical practice. ${ }^{13}$ They are useful to detect early respiratory involvement and provide a target parameter for followup, prognosis, and assessment of treatment response.

In order to prevent and delay respiratory complications and extend the survival of children with $\mathrm{CF}$, we propose to assess the course of lung 
function during the first 3 years of life and identify the factors affecting it.

\section{PATIENTS AND METHODS}

Design: Observational, retrospective, analytical cohort study carried out on a database developed based on the systematic, prospective recording of information about all patients with CF seen at the hospital.

Study population: Children younger than 36 months, with a confirmed diagnosis of CF (2 positive sweat tests or 2 mutations in the cystic fibrosis transmembrane conductance regulator gene $[C F T R])$ seen at the Respiratory Center “Dr. Alberto R. Álvarez" of Hospital de Niños Ricardo Gutiérrez between 2008 and 2016. They were required to have at least 2 technicallyacceptable lung function tests, as per international guidelines, ${ }^{14}$ the first test must have been done before 12 months old and the subsequent ones, at least 6 months after the first test. Preterm infants (gestational age $\leq 36$ weeks) or patients with congenital heart disease and pulmonary hypertension were excluded.

Lung function tests: These were done using the Sensormedics 2600 equipment. Patients had to be clinically stable and not presenting symptoms of an acute respiratory infection in, at least, the 3 weeks prior to the test. Patients were sedated with chloral hydrate $75 \mathrm{mg} / \mathrm{kg} /$ dose administered orally. Forced flow-volume curves were obtained using the partial volume rapid thoracoabdominal compression technique. The maximal flow at functional residual capacity $\left(\mathrm{V}_{\max }\right.$ FRC) was reported. Results were described as an average of the 4 best technically acceptable maneuvers with a difference of up to $10 \%$. This parameter reflects small airways caliber. It was expressed as an absolute value in $\mathrm{mL} / \mathrm{s}$ and Z-score, as per the reference values proposed by Hoo et al. ${ }^{15}$ Eosinophilic airway inflammation was assessed using the Ecomedics CLD 88 chemiluminescence analyzer (Dürnten, Switzerland) based on the online tidal breathing technique. A DENOX 88 module was added to the equipment to ensure that the patient was breathing in nitric oxide-free ambient air and the expiratory flow was regulated at $50 \mathrm{~mL} / \mathrm{s}$, according to international standards. ${ }^{16}$

Periodic assessment of bronchial secretions: Given the included patients' inability to cough effectively at this age, the presence of airway bacteria was assessed using cough swabs (at least 4 annual specimens were obtained).
Database: The following outcome measures were obtained: neonatal history, age at the time of diagnosis, type of genetic mutation, pancreatic insufficiency, anthropometric data, exhaled nitric oxide levels.

Statistical analysis: Qualitative outcome measures were reported as absolute values and percentage. Quantitative outcome measures were stated as mean and standard deviation (SD) or as median and interquartile range (IQR), as applicable. The Z-score change in the $\mathrm{V}_{\max }$ FRC was assessed based on the difference between the Z-score for the final and initial lung function tests, and the null hypothesis of no difference was evaluated using the $t$ test for paired samples or the Wilcoxon signed rank test, depending on the observed distribution. Continuous outcome measures were compared using the t test or the Wilcoxon rank sum test (MannWhitney), depending on the observed distribution. Qualitative outcome measures were compared using the $\chi^{2}$ test or Fisher's test, as applicable. A value of $p<0.05$ was considered significant. The Stata software, version 13, was used.

Ethical considerations: The study was approved by the Ethics Research Committee of Hospital de Niños Ricardo Gutiérrez.

\section{RESULTS}

A total of 48 patients with confirmed diagnosis of CF at 2 to 29 months of age, followed in the Respiratory Center between 2008 and 2016, were included. Their median age at the time of CF diagnosis was 3 months old, with an IQR of 2 to 4 months. In 41 patients ( $85 \%$ ), diagnosis was confirmed by newborn screening. Table 1 details the baseline characteristics of included patients.

All patients had at least 2 lung function tests with a median time interval of 14 months (IQR: 10 to 17 months). Twenty-three patients ( $45.8 \%$ ) had 3 lung function tests with a median time interval of 16.3 months (IQR: 14 to 19 months). The clinical, functional, anthropometric, and infectious characteristics of each lung function test are detailed in Table 2.

The first lung function test was at 5 months old (IQR: 3 to 8 months) and the median Z-score for the $\mathrm{V}_{\max }$ FRC was -0.05 (IQR: -1.09 to 1.08). A decreased lung function was evidenced as determined by the change in the median Z-score of $\mathrm{V}_{\max }$ FRC between the first and the last assessment of -0.32 , with an IQR of -1.11 to $0.25 ; p=0.045$.

The decrease in $\mathrm{V}_{\max }$ FRC was more notorious in the patients who had 3 lung function 
determinations. The change in the median Z-score of $\mathrm{V}_{\text {max }}$ FRC was -0.61 (IQR: -1.68 to -0.19 ; $p=0.0033$ ). Figure 1 shows the course of lung function during the first months of life.

Patients with bacterial respiratory infections had a worse lung function course compared to those without infection. Methicillin-sensitive Staphylococcus aureus (MSSA) infections evidenced a decrease of $\mathrm{V}_{\max }$ FRC of -0.75 (-1.22 to -0.28$)$ versus 0.61 ( -0.7 to 1.9$)$ in those without infection $(p=0.01)$. Patients who had methicillin-resistant Staphylococcus aureus (MRSA) infections showed a greater involvement of their lung function. The decrease in their $\mathrm{V}_{\max }$ FRC was $-1.38(-2.25$ to -0.5$)$ versus $0.02(-0.5$ to $0.5 ; p=0.006)$ in those without infection. Patients with Pseudomonas aeruginosa

TABLE 1. Baseline characteristics of included patients

\begin{tabular}{|c|c|}
\hline Characteristics & $\mathrm{n}=48$ \\
\hline Female sex, n $(\%)$ & $24(50)$ \\
\hline Gestational age (weeks)* & $39 \pm 1.5$ \\
\hline Birth weight, $\mathrm{kg}^{\star *}$ & $3.2(2.9-3.5)$ \\
\hline Meconium ileus, n (\%) & $1(2)$ \\
\hline $\mathrm{O}_{2}$ requirement at birth, $\mathrm{n}(\%)$ & $4^{\star \star *}(8)$ \\
\hline AMV requirement at birth, $\mathrm{n}(\%)$ & $0(0)$ \\
\hline Maternal smoking during pregnancy, n (\%) & $0(0)$ \\
\hline Age at diagnosis, months old ${ }^{* *}$ & $3(2-4)$ \\
\hline Newborn screening diagnosis, $\mathrm{n}(\%)$ & $41(85.4)$ \\
\hline \multicolumn{2}{|l|}{ CFTR genotype: $\mathrm{n}(\%)$} \\
\hline Homozygous for the Delta F508 & $19(39.6)$ \\
\hline Heterozygous for the Delta F508 & $22(45.8)$ \\
\hline Mutation other than Delta F508 & $3(6.3)$ \\
\hline Negative test for studied mutations & $4(8.3)$ \\
\hline Pancreatic insufficiency, n (\%) & $43(89.6)$ \\
\hline \multicolumn{2}{|l|}{ Age at the first isolation ${ }^{* *}, \mathrm{n}(\%)$ : } \\
\hline Pseudomonas aeruginosa & 7 months (4-13); 33 (68.7) \\
\hline Methicillin-sensitive Staphylococcus aureus & 4.5 months $(3-7) ; 36$ (75) \\
\hline Methicillin-resistant Staphylococcus aureus & 8 months (3-18); 15 (31.3) \\
\hline Burkholderia cepacia & 7 months (5-12.5); 4 (8.3) \\
\hline
\end{tabular}

${ }^{*}$ Mean $\pm \mathrm{SD}$; ${ }^{* *}$ Median and interquartile range; ${ }^{* * *} 1,3.5$, and 34 days of oxygen, respectively.

AMV: assisted mechanical ventilation; $\mathrm{O}_{2}$ : oxygen; $\mathrm{CFTR}$ : cystic fibrosis transmembrane conductance regulator.

TABLE 2. Patient characteristics for each lung function test

\begin{tabular}{|c|c|c|c|}
\hline Characteristics & $\begin{array}{c}1^{\text {st }} \text { assessment } \\
n=48\end{array}$ & $\begin{array}{c}2^{\text {nd }} \text { assessment } \\
n=48\end{array}$ & $\begin{array}{c}3^{\text {rd }} \text { assessment } \\
n=22\end{array}$ \\
\hline Age, months old* & $5(3-8)$ & $12.5(12-18)$ & $20.5(17-24)$ \\
\hline Weight, kg* & $6.3(5.3-7.2)$ & $9.7(8.8-10.8)$ & $11.1(10.4-12)$ \\
\hline Weight Z-score & $-1.2(-2.3$ to -0.5$)$ & $-0.38(-1.2$ to 0.22$)$ & $-0.04(-1.18$ to 0.22$)$ \\
\hline Height, $\mathrm{cm}^{*}$ & $64(58-67)$ & $78(72-81)$ & $81(77-86)$ \\
\hline Height Z-score & $-1.03(-2.1$ to -0.46$)$ & $-0.93(-1.35$ to -0.18$)$ & $-0.89(-1.56$ to -0.04$)$ \\
\hline Body mass index* & $15.7(15-16.8)$ & $16.2(15.4$ to 17.5$)$ & $16.5(15.2$ to 17.7$)$ \\
\hline $\mathrm{V}_{\max } \mathrm{FRC}, \mathrm{mL} / \mathrm{sec}^{*}$ & 173 (92 to 273 ) & 285 (154 to 371$)$ & $226(156$ to 434$)$ \\
\hline $\mathrm{V}_{\text {max }}^{\text {max }}$ FRC, Z-score* & $-0.05(-1.09$ to 1.08$)$ & $-0.285(-1.65$ to 0.63$)$ & $-1.28(-2,45$ to 0.47$)$ \\
\hline FeNO, $\mathrm{ppb}^{*}$ & $3.2(0.7$ to 5.5$)$ & $4.1(0.4$ to 5,6$)$ & $5.4(3.3$ to 8.5$)$ \\
\hline Respiratory rate ${ }^{* *}$ & $44 \pm 9$ & $38 \pm 10$ & $36 \pm 10$ \\
\hline Heart rate ${ }^{* *}$ & $122 \pm 10$ & $112 \pm 12$ & $105 \pm 17$ \\
\hline $\mathrm{SpO}_{2}, \% * *$ & $98 \pm 1.5$ & $97 \pm 1.3$ & $98 \pm 3$ \\
\hline Patients with PAE, no. $(\%)^{* * *}$ & $15 / 47(32)$ & $15 / 43(34.8)$ & $14 / 22(45.4)$ \\
\hline Patients with MSSA, no. $(\%)$ & $24 / 47(51)$ & $24 / 44(54.5)$ & $12 / 22(54.5)$ \\
\hline Patients with MRSA, no. (\%) & $6 / 47(12.8)$ & $8 / 44(18)$ & $4 / 19(21)$ \\
\hline
\end{tabular}

${ }^{*}$ Median and interquartile range. ${ }^{* *}$ Mean \pm SD.

${ }^{* * *}$ No patient had chronic PAE infection. The microorganism was eliminated in $100 \%$ of cases.

Vmax FRC: maximal flow at functional residual capacity, a parameter that reflects small airway caliber.

FeNO: fractional exhaled nitric oxide; PAE: Pseudomonas aeruginosa; MSSA: methicillin-sensitive Staphylococcus aureus;

MRSA: methicillin-resistant Staphylococcus aureus. 
(PAE) infections had a greater decrease in $\mathrm{V}_{\max }$ FRC than those without infection, although such difference was not statistically significant $(p=0.61)$.

Neither sex nor the type of genetic mutation were associated with the course of lung function (Table 2). Conversely to the functional aspect, nutritional recovery throughout the study was really good. The delta of the change in the weight $Z$-score between the first and the last test was 0.91 SD (IQR: 0.02 to 1.8). The assessment of eosinophilic bronchial inflammation by measuring exhaled nitric oxide levels did not show high levels for any patient (Table 2).

\section{DISCUSSION}

This study evidenced that children with CF had a normal lung function at 6 months old according to the partial volume rapid thoracoabdominal compression technique; however, lung function deteriorated progressively during the first 3 years of life. These findings were associated with Staphylococcus aureus respiratory infections, especially MRSA, but were not connected with the type of genetic mutation or sex.

Ranganathan et al., in a multicenter study done in London before the newborn screening was introduced, reported that young children with CF had a decreased lung function at the time of diagnosis and that they did not recover it in the first 2 years of life, in spite of management at specialized facilities. ${ }^{17}$ Linnane et al., in a crosssectional study, assessed Australian infants after CF diagnosis was confirmed based on the newborn screening. Similarly to our study, they showed that lung function was normal after diagnosis and that it worsened after 1 year. Unlike our study, this occurred regardless of respiratory infections. ${ }^{18}$ Subsequently, a prospective, cohort study done in Australia assessed 28 children younger than 2 years diagnosed with $C F$ based on a newborn screening compared to healthy historical controls. That study performed lung function tests and bronchoalveolar lavage at 6 months and before 2 years old. It reported that children with CF suffered respiratory involvement in the first months of life and that their lung function worsened progressively. These findings were associated with PAE and Staphylococcus aureus infections and neutrophilic airway inflammation. ${ }^{19}$ Recently, the London Cystic Fibrosis Collaboration published a prospective, longitudinal study that compared healthy controls to 62 children with CF at 3 months old, 1 year old and 2 years old using 3 different lung function measurement techniques. Contrary to prior studies, that study did not evidence a progressive worsening of lung function or significant difference between groups. Bacterial respiratory infections were not associated with the course of lung function. ${ }^{20}$ Such

\section{FIGURE 1. Course of lung function in patients with cystic fibrosis (in months old), $n=48$}

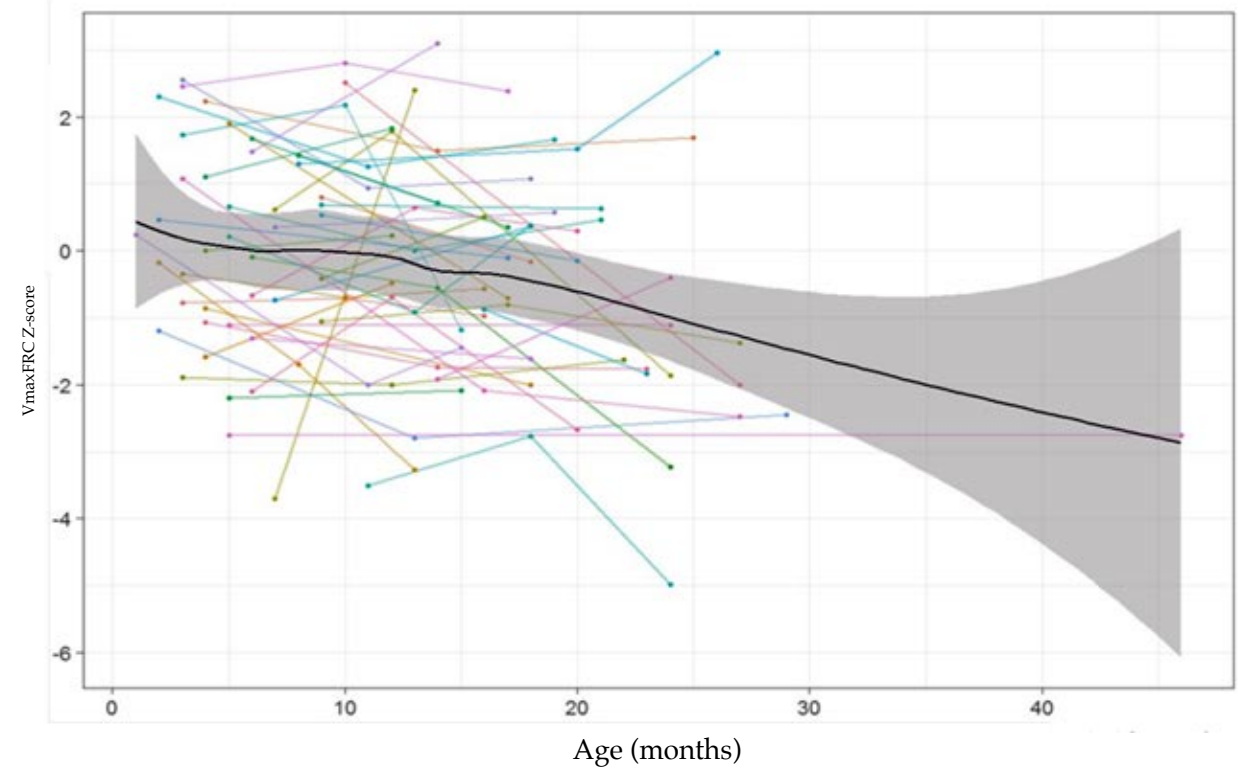

Vmax FRC: maximal flow at functional residual capacity, a parameter that reflects small airway caliber. 
discrepancies between the cohorts of Australian and London CF patients who had lung function tests since their first months of life may be due to technical and methodological differences in relation to lung function and control tests used. ${ }^{5}$

The publications about the impact of bacterial respiratory infections on lung function in preschool and schoolchildren with CF are more common, but outcomes have been contradictory. ${ }^{21-23}$ However, most of the evidence claims that PAE and Staphylococcus aureus bacterial respiratory infections affect spirometry parameters. In our study, the impact of PAE respiratory infections on lung function was possibly not evidenced due to the low number of patients with positive cultures and the fact that only a single or intermittent microorganisms were isolated in our patients.

In children with CF unable to cough effectively, the most accurate method to detect the presence of bacteria in the lower airways is bronchoalveolar lavage. ${ }^{24}$ Since it is an invasive method, it is not routinely done, so the presence of bacteria in the airway was assessed using cough swabs. However, the sensitivity of this method is not optimal and varies considerably among the different studies. Notwithstanding this, for those patients with a poor clinical course and repeatedly negative cough swabs material, it is recommended to perform an induced sputum or bronchoalveolar lavage..$^{25,26}$

This is the first study to report about the course of lung function in children with CF since the first months of life in Argentina. Although the retrospective design of this study represents potential information biases due to the inaccuracy of medical records, a standardized follow-up and the objective recording of clinical controls, together with the surveillance of bacterial infections, helped to minimize such risk.

Another of the limitations of this study was its lack of a control group. The need for sedation to perform lung function tests and their complexity hindered the possibility of establishing a control group of healthy children.

The measurement of lung function with the high volume rapid thoracoabdominal compression technique is preferred over the partial volume technique because it is more sensitive to detect obstructive involvement in children with CF. ${ }^{27,28}$ Besides, the disadvantages of the latter are that it provides a single functional parameter and its higher intra- and inter-subject variability. However, Godfrey et al. evidenced a high correlation between both tests, which demonstrated that both techniques could be used interchangeably in sick children. ${ }^{29}$ The difference in the method used to measure lung function may account for some differences with other published studies. In recent years, the use of the lung clearance index (LCI) has allowed to assess lung ventilation heterogeneity using a washout method. In preschool children with $C F$, this technique is more sensitive than a spirometry but, in young children, it is complementary to the rapid thoracoabdominal compression technique, which increases the detection of functional involvement. ${ }^{30} \mathrm{~A}$ recently published study reported that $40 \%$ of children with CF aged 8 weeks old had functional involvement according to this method. ${ }^{31}$

Another limitation of this study is that it did not compare functional involvement and structural damage. A high-resolution computed tomography of the lung directly shows airway damage and is complementary to lung function tests. ${ }^{32}$ However, its routine use in young children is controversial due to radiation..$^{33}$

Lung involvement in children with CF starts in the first months of life or, possibly, in the uterus. ${ }^{34}$ Since many children are asymptomatic, lung function tests allow for an early detection. Longitudinal studies have revealed that functional parameters obtained in the first months of life follow the same path during preschool and school age, which results in a useful tool to predict lung function in future years. ${ }^{35}$ It is critical to understand the factors responsible for the initiation and course of respiratory involvement from an early age because $90 \%$ of morbidity and mortality is caused by lung involvement. ${ }^{5}$ However, these tests are yet to be implemented routinely in clinical practice. The high costs, the scarce availability of commercial equipment, the lack of reference values, technical difficulties, and mainly the need for sedation hinder their implementation.

\section{CONCLUSION}

Lung function in children with CF worsens progressively during their first 3 years of life. These findings were associated with Staphylococcus aureus bacterial respiratory infections, especially MRSA. It is necessary to maximize infection prevention measures and to implement more aggressive approaches to eliminate infections in order to delay the progression of disease and minimize any potential damage during a critical stage of lung development and growth. 


\section{REFERENCES}

1. Walters S, Mehta A. Epidemiology of cystic fibrosis. In: Hodson ME, Geddes DM, Bush A (eds.). Cystic Fibrosis. $3^{\text {rd }}$ ed. London, United Kingdom: Hodder Arnold; 2007. Pages.21-45.

2. Comités Nacionales de Neumonología, Nutrición, Gastroenterología y Grupo de Trabajo de Kinesiología. Guía de diagnóstico y tratamiento de pacientes con fibrosis quística. Actualización. [Accessedon: April 5 ${ }^{\text {th }}, 2019$ ]. Available at: https: / / www.sap.org.ar/uploads/consensos/gu-iacuteade-diagn-oacutestico- y-tratamiento-de-pacientesconfibrosis-qu-iacutestica- actualizaci-oacuten.pdf.

3. Kerem E, Conway S, Elborn S, Heijerman H; Consensus Committee. Standards of care for patients with cystic fibrosis: a European consensus. J Cyst Fibros. 2005; 4(1):726.

4. Dankert-Roelse JE, teMeerman GJ, Marrtjin A, Ten Kate LP, et al. Survival and clinical outcome in patients with cystic fibrosis, with or without neonatal screening. J Pediatr. 1989; 114(3):362-7.

5. Bush A, Sly P. Evolution of cystic fibrosis lung function in the early years. Curr Opin Pulm Med. 2015; 21(6):602-8.

6. Ranganathan SC, Dezateux C, Bush A, Carr SB, et al. Airway function in infants newly diagnosed with cystic fibrosis. Lancet. 2001; 358(9297):1964-5.

7. Dakin CJ, Numa AH, Wang H, Morton JR, et al. Inflammation, infection, and pulmonary function in infants and young children with cystic fibrosis. Am J RespirCrit Care Med. 2002; 165(7):904-10.

8. DavisSD, Fordham LA, Brody AS, Noah TL, etal.Computed tomography reflects lower airway inflammation and tracks changes in early cystic fibrosis. Am J Respir Crit Care Med. 2007; 175(9):943-50.

9. Long FR, Williams RS, Castile RG. Structural airway abnormalities in infants and young children with cystic fibrosis. J Pediatr. 2004; 144(2):154-61.

10. Martinez TM, Llapur CJ, Williams TH, Coates C, et al. High-resolution computed tomography imaging of airway disease in infants with cystic fibrosis. Am J Respir Crit Care Med. 2005; 172(9):1133-8.

11. ArmstrongDS,HookSM,Jamsen KM,Nixon GM, etal.Lower airway inflammation in infants with cystic fibrosis detected by newborn screening. Pediatr Pulmonol. 2005; 40(6):500-10.

12. Khan TZ, Wagener JS, Bost T, Martinez J, et al. Early pulmonary inflammation in infants with cystic fibrosis. Am J Respir Crit Care Med. 1995; 151(4):1075-82.

13. Smyth AR, Bell SC, Bojcin S, Bryon M, et al. European Cystic Fibrosis Society Standards of Care: Best Practice guidelines. J Cyst Fibros. 2014; 13(Suppl 1):S23-42.

14. American Thoracic Society; European Respiratory Society. ATS/ERS statement: raised volume forced expirations in infants: guidelines for current practice. Am J Respir Crit Care Med. 2005; 172(11):1463-71.

15. Hoo AF, Dezateux C, Hanrahan JP, Cole TJ, et al. Sexspecific prediction equations for $\operatorname{Vmax}(\mathrm{FRC})$ in infancy: a multicenter collaborative study. Am J RespirCrit Care Med. 2002; 165(8):1084-92.

16. American Thoracic Society; European Respiratory Society. ATS/ERS Recommendations forStandardized Procedures for the Online and Offline Measurement of Exhaled Lower Respiratory Nitric Oxide and Nasal Nitric Oxide, 2005. Am J Respir Crit Care Med. 2005; 171(8):912-30.

17. Ranganathan SC, Stocks J, Dezateux C, Bush A, et al. The evolution of airway function in early childhood following clinical diagnosis of cystic fibrosis. Am J RespirCrit Care Med. 2004; 169(8):928-33.

18. Linnane BM, Hall GL, Nolan G, Brennan S, et al. Lung function in infants with cystic fibrosis diagnosed by newborn screening. Am J Respir Crit Care Med. 2008; 178(12):1238-44.

19. Pillarosetti N, Williamson E, Linnane B, Skoric B, et al. Infection, inflammation, and lung function decline in infants with cystic fibrosis. Am J Respir Crit Care Med. 2011;184(1):7581.

20. Davies G, Stocks J, Thia LP, Hoo AF, et al. Pulmonary function deficits in newborn screened infants with cystic fibrosis managed with standard UK care are mild and transient. Eur Respir J. 2017; 50(5):1700326.

21. Sanders D, Emerson J, Ren C, Schechter M, et al. Early childhood risk factors for decreased FEV1 at age six to seven years in young children with cystic fibrosis. Ann Am Thorac Soc. 2015; 12(8): 1170-6.

22. Cogen J, Emerson J, Sanders J, Ren C, et al. Risk factors for lung function decline in a large cohort of young cystic fibrosis patients. Pediatr Pulmonol. 2015; 50(8):763-70.

23. Sawicki GS, Rasouliyan L, Ren CL. The impact of MRSA on lung function in patients with cystic fibrosis. Am J Respir Crit Care Med. 2009; 179(8):734-5.

24. Rosenfeld M, Emerson J, Accurso F, Armstrong D, et al. Diagnostic accuracy of oropharyngeal cultures in infants and young children with cystic fibrosis. Pediatr Pulmonol. 1999; 28(5):321-8.

25. Equi AC, Pike SE, Davies J, Bush A. Use of cough swabs in a cystic fibrosis clinic. Arch Dis Child. 2001; 85(5):438-9.

26. Ahmed B, Bush A, Davies J. How to use: bacterial cultures in diagnosing lower respiratory tract infections in cystic fibrosis. Arch Dis Child Educ Pract Ed. 2014; 99(5):181-7.

27. RanganathanSC, Bush A, Dezateux C, CarrSB, etal. Relative ability of full and partial forced expiratory maneuvers to identify diminished airway function in infants with cystic fibrosis. Am J Respir Crit Care Med. 2002; 166(10):1350-7.

28. Turner DJ, Lanteri CJ, LeSouef PN, Sly PD. Improved detection of abnormal respiratory function using forced expiration from raised lung volume in infants with cystic fibrosis. Eur Respir J. 1994; 7(11):1995-9.

29. Bar-Yishay E, Springer C, Hevroni A, Godfrey S. Relation between partial and raised volume forced expiratory flows in sick infants. Pediatr Pulmonol. 2011; 46(5):458-63.

30. Lum S, Gustafsson P, Ljungberg H, Hülskamp G, et al. Early detection of cystic fibrosis lung disease: multiplebreath washout versus raised volume tests. Thorax. 2007; 62(4):341-7.

31. Kieninger E, Yammine S, Korten I, Anagnostopoulou P, et al. Elevated lung clearance index in infants with cystic fibrosis shortly after birth. Eur Respir J. 2017; 50(5):1700580.

32. Tiddens HA. Chest computed tomography scans should be considered as a routine investigation in cystic fibrosis. Paediatr Respir Rev. 2006; 7(3):202-8.

33. Cooper P, MacLean J. High-resolution computed tomography (HRCT) should not be considered as a routine assessment method in cystic fibrosis lung disease. Paediatr Respir Rev. 2006; 7(3):197-201.

34. Ramsey KA, Ranganathan S. Interpretation of lung function in infants and young children with cystic fibrosis. Respirology. 2014; 19(6):792-9.

35. KozlowskaWJ,BushA,WadeA, AuroraP, etal.Lung function from infancy to the preschool years after clinical diagnosis of cystic fibrosis. Am J Respir Crit Care Med. 2008; 178(1):42-9. 